Supporting Information

\title{
Layered Perovskites Enhanced Perovskite Photodiodes
}

Ruiming Li, Yalun Xu, Wei Li, Yanyan Li, Jiali Peng, Mingfei Xu, and Qianqian Lin*

Key Lab of Artificial Micro- and Nano-Structures of Ministry of Education of China, School of Physics and Technology, Wuhan University, Wuhan 430072, P. R. China

Corresponding Author:

*E-mail: q.lin@whu.edu.cn

1. Experimental details

2. Supporting figures 


\section{Experimental Section}

\section{Precursor Preparation:}

The three-dimensional (3D) perovskite $\mathrm{FA}_{0.83} \mathrm{Cs}_{0.17} \mathrm{PbI}_{3}$ precursor solution $(1.2 \mathrm{M})$ was obtained by adding $171.3 \mathrm{mg}$ formamidinium iodide (FAI, Greatcell Solar), $53.0 \mathrm{mg}$ cesium iodide (CsI, 99.9\%, Sigma-Aldrich), and $553.2 \mathrm{mg}$ lead iodide ( $\mathrm{PbI}_{2}, 99.99 \%$, TCI Chemicals) into the mixed solvent of $800 \mu \mathrm{L}$ N,N-Dimethylformamide (DMF, Aladdin) and $200 \mu \mathrm{L}$ dimethyl sulfoxide (DMSO, Aladdin). The two-dimensional (2D) perovskite $\mathrm{PA}_{2} \mathrm{PbI}_{4}$ precursor solution $(0.25 \mathrm{M})$ was obtained by adding $93.5 \mathrm{mg}$ propylammonium iodide (PAI, 99.5\%, Xi' an Polymer Light Technology Corp) and $115.3 \mathrm{mg} \mathrm{PbI} 2$ into the mixed solvent of $800 \mu \mathrm{L}$ DMF and $200 \mu \mathrm{L}$ DMSO, and was diluted into $0.125 \mathrm{M}$ and $0.0625 \mathrm{M}$. Then, $20 \mu \mathrm{L}$ $\mathrm{PA}_{2} \mathrm{PbI}_{4}$ solutions $(0 \mathrm{M}, 0.0625 \mathrm{M}, 0.125 \mathrm{M}$, and $0.25 \mathrm{M})$ were added into $100 \mu \mathrm{L}$ $\mathrm{FA}_{0.83} \mathrm{Cs}_{0.17} \mathrm{PbI}_{3}$ precursor solution to form $\left(\mathrm{PA}_{2} \mathrm{PbI}_{4}\right)_{\mathrm{x}}\left(\mathrm{FA}_{0.83} \mathrm{Cs}_{0.17} \mathrm{PbI}_{3}\right)_{1-\mathrm{x}}$ solution $(1 \mathrm{M}, \mathrm{x}=0$, $0.01,0.02,0.04)$ respectively just before the spin-coating.

\section{Device Fabrication:}

All pre-patterned indium tin oxide (ITO)-coated glass substrates were ultrasonically cleaned sequentially in deionized water, isopropanol $\left(\mathrm{C}_{3} \mathrm{H}_{8} \mathrm{O}, \geq 99.5 \%\right.$, Macklin), and ethanol $\left(\mathrm{C}_{2} \mathrm{H}_{6} \mathrm{O}\right.$, $\geq 95 \%$, Sinopharm Chemical Reagent Co., Ltd) for $10 \mathrm{~min}$, respectively, and dried by a compressed dry air. Then the substrates were treated with UV-ozone for $15 \mathrm{~min} .1 .5 \mathrm{mg}$ poly[bis(4-phenyl)(2,4,6-trimethylphenyl)amine] (PTAA, Mn=6000 15000, Xi'an Polymer Light Technology Corp) was dissolved in $1 \mathrm{~mL}$ toluene $\left(\mathrm{C}_{7} \mathrm{H}_{8}, \geq 99.5 \%\right.$, Sinopharm Chemical Reagent Co., Ltd). Then the PTAA precursor was spin-coated on the ITO substrates at 6000 $\mathrm{rpm}$ for $30 \mathrm{~s}$ and baked at $100^{\circ} \mathrm{C}$ for $10 \mathrm{~min}$ in argon-filled glove box. Polyethylenimine ethoxylated (PEIE, 37wt $\%$ in $\mathrm{H}_{2} \mathrm{O}$, Sigma-Aldrich) was diluted into $0.2 \mathrm{wt} \%$ with 2methoxyethanol $\left(\mathrm{C}_{3} \mathrm{H}_{8} \mathrm{O}_{2}\right.$, Greagent $)$ and deposited on the top of PTAA by spin coating at 
$5000 \mathrm{rpm}$ for $60 \mathrm{~s}$ in air. Then, the PEIE films were annealed at $100^{\circ} \mathrm{C}$ for $10 \mathrm{~min}$ in glove box. Then, the 2D-3D perovskite $\left(\mathrm{PA}_{2} \mathrm{PbI}_{4}\right)_{\mathrm{x}}\left(\mathrm{FA}_{0.83} \mathrm{Cs}_{0.17} \mathrm{PbI}_{3}\right)_{1-\mathrm{x}}$ solution $(1 \mathrm{M}, \mathrm{x}=0,0.01$, 0.02, 0.04) was spin-coated at $4000 \mathrm{rpm}$ for $60 \mathrm{~s}$ in glove box. $200 \mu \mathrm{L}$ ethyl acetate (EA, $99.8 \%$, Aladdin) was dropped onto the spinning film to accelerate the crystallization process at $25 \mathrm{~s}$ after the trigger of spin-coating. The deposited perovskite films were annealed on the hot plate at $155^{\circ} \mathrm{C}$ for $0.5 \mathrm{~h}$ in air. Fullerene-C70 (>99\%, HPLC, Luminescence Technology Corp) and bathocuproine (BCP, $>99 \%, \mathrm{Xi}$ 'an Polymer Light Technology Corp) were successively deposited on top of perovskite layer as electron transport layers by thermal evaporation. Finally, metal electrodes $(80 \mathrm{~nm} \mathrm{Cu})$ were deposited on $\mathrm{BCP}$ using a thermal evaporation with shadow masks to complete the perovskite photodetector (PPD) fabrication. For the comparison of photovoltaic device performance, we replace the PTAA layer with an optimized poly[ $N, N^{\prime}$-bis(4-butylphenyl)- $N, N^{\prime}$-bis(phenyl)-benzidine $]$

(ploy-TPD, Mn=20000 60000, Xi'an Polymer Light Technology Corp) layer, which was spin-coated with a $2 \mathrm{mg} / \mathrm{mL}$ solution in chlorobenzene at $2000 \mathrm{rpm}$ for $30 \mathrm{~s}$ in glove box. Then, the polyTPD films was heated at $100^{\circ} \mathrm{C}$ for $10 \mathrm{~min} .0 .5 \mathrm{mg}$ poly[(9,9-bis(3'-((N,N-dimethyl)-Nethylammonium)-propyl)-2,7-fluorene)-alt-2,7-(9,9-dioctylfluorene)] (PFNBr, MW>10,000, Luminescence Technology Corp) was dissolved in $1 \mathrm{~mL}$ methanol $\left(\mathrm{CH}_{4} \mathrm{O}, 99.5 \%\right.$, Aladdin $)$ and spin-coated at $1000 \mathrm{rpm}$ to replace the PEIE layer, and the C70 layer was replaced with a $25 \mathrm{~nm}$ C60 layer.

\section{Characterization:}

The morphology of perovskite films was recorded by a TESCAN MIRA3 field-emission scanning electron microscope at an accelerating voltage of $5 \mathrm{keV}$. The $\mathrm{X}$-ray diffraction (XRD) of the prepared films were characterized using a D8 Advance X-ray diffractometer $\left(\mathrm{Cu} \mathrm{K} \alpha=1.5418 \AA\right.$ ) with a scanning range from $9.6^{\circ}$ to $46^{\circ}$. The absorption spectra were measured with a spectrometer (ThetaMetrisis, FR-Basic-UV/NIR-HR) via reflectance 
corrected transmittance. Steady-state photoluminescence spectra were recorded using a Morpho Nova spectrometer with the excitation of a $450 \mathrm{~nm} \mathrm{CW}$ laser. The time-resolved photoluminescence (TRPL) was acquired using the time-correlated single-photon counting technique (TimeHarp 260 PICO Single, PicoQuant GmbH), and the excitation was provided by a picosecond diode laser (405 nm, PiL040X, NKT photonics). Current-voltage curves of the devices were collected by a B1500A semiconductor analyzer (Keysight) in dark. Temporal response was measured using a picosecond pulse laser (405 nm, PiL040X, NKT photonics) or LEDs (405 nm, $528 \mathrm{~nm}, 592 \mathrm{~nm}, 630 \mathrm{~nm}, 780 \mathrm{~nm}$, white light, Thorlabs) modulated with an arbitrary wave function generator (Keysight, 33500B), and the transient photocurrent responses were recorded with a digital storage oscilloscope (LeCroy Waverunner 8254). Noise current spectrum was recorded by a spectrum analyzer (Keysight N9915A FieldFox) with a current pre-amplifier (Stanford Research System, SR570). Lightintensity dependent responsivity (LDR) was determined using a $532 \mathrm{~nm} \mathrm{CW}$ laser (Yuanxin Optoelectronics, LSR532H-2W) as light source with a set of neutral density pre-filters and a motorized round continuously variable neutral density filter (maximal OD4 attenuation) to vary the light intensity. External quantum efficiency (EQE) was measured with an AAA class solar simulator (SAN-EI, XES-50S2) as light source, coupled with a grating monochromator (BOCI, WDG30(50)-Z) and an optical chopper (Thorlabs, MC2000B), and the photocurrent was recorded with a lock-in amplifier (SR830, Stanford Research). 


\section{Supporting figures}

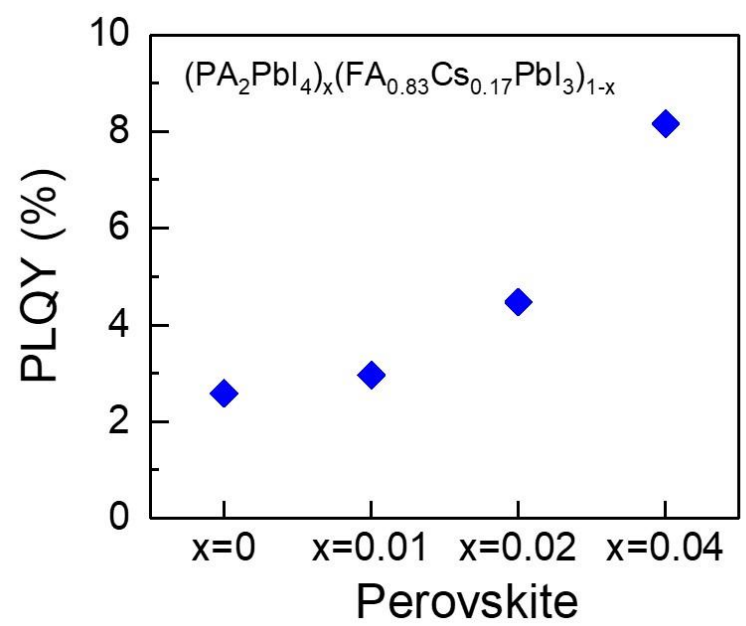

Figure S1. Comparison of the PLQY of the $\left(\mathrm{PA}_{2} \mathrm{PbI}_{4}\right)_{\mathrm{x}}\left(\mathrm{FA}_{0.83} \mathrm{Cs}_{0.17} \mathrm{PbI}_{3}\right)_{1-\mathrm{x}}$ perovskite films with $\mathrm{x}=0,0.02,0.04,0.08$, measured in air.

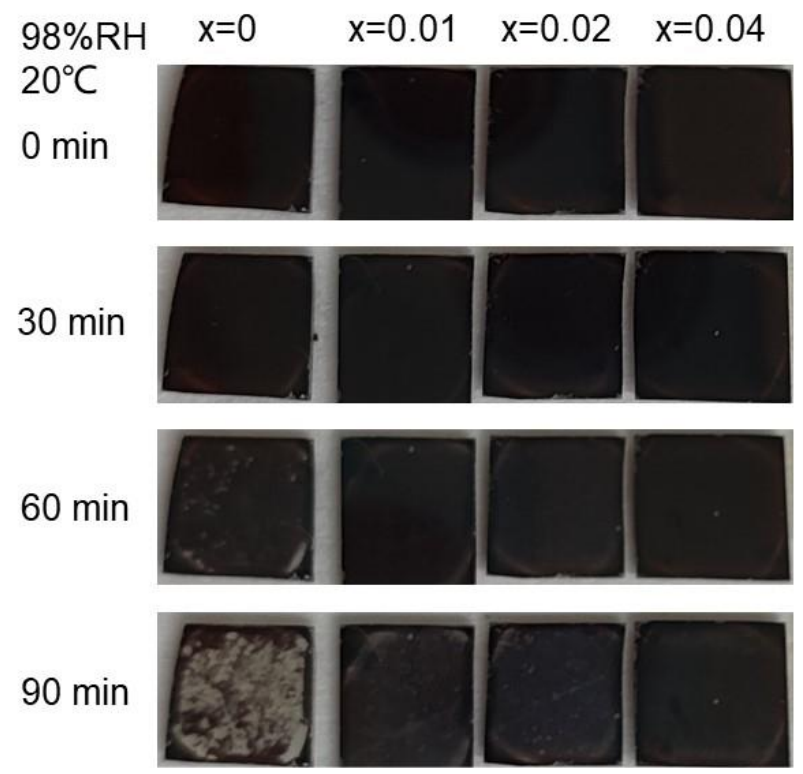

Figure S2. Comparison of the stability of the $\left(\mathrm{PA}_{2} \mathrm{PbI}_{4}\right)_{\mathrm{x}}\left(\mathrm{FA}_{0.83} \mathrm{Cs}_{0.17} \mathrm{PbI}_{3}\right)_{1-\mathrm{x}}$ perovskite films in air with $\mathrm{x}=0,0.01,0.02,0.04$. 


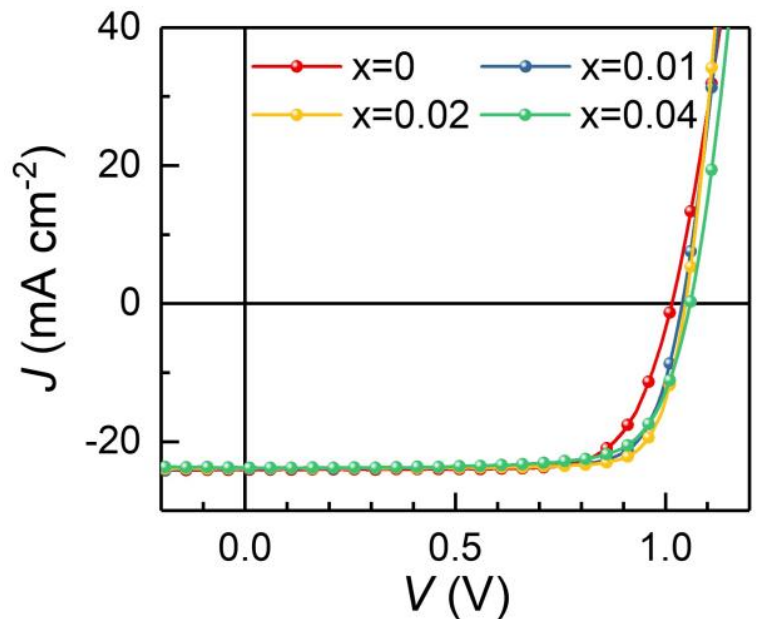

Figure S3. Comparison of the current density-voltage $(J-\mathrm{V})$ of the $\left(\mathrm{PA}_{2} \mathrm{PbI}_{4}\right)_{\mathrm{x}}\left(\mathrm{FA}_{0.83} \mathrm{Cs}_{0.17} \mathrm{PbI}_{3}\right)_{1-\mathrm{x}}$ perovskite solar cells (PSCs) with $\mathrm{x}=0,0.01,0.02,0.04$ under 1 sun irradiation.

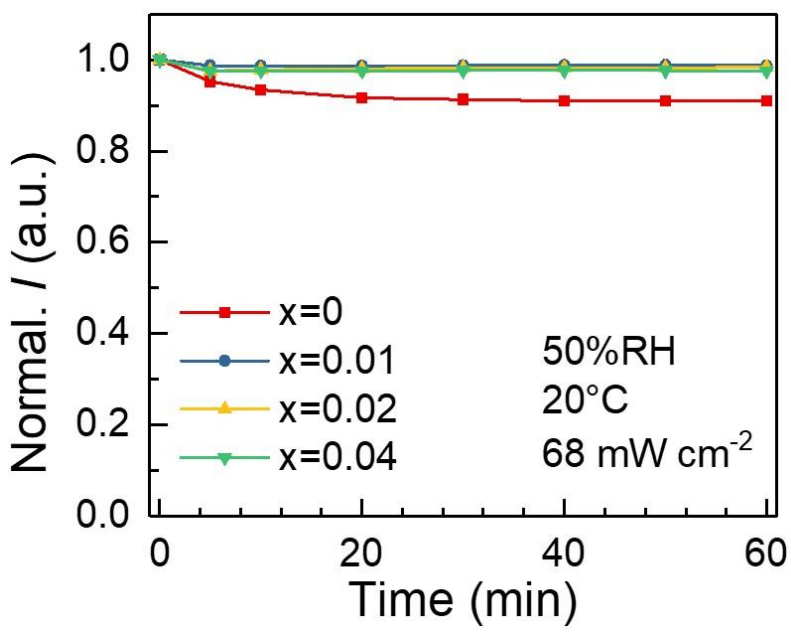

Figure S4. Comparison of the device stability of $\left(\mathrm{PA}_{2} \mathrm{PbI}_{4}\right)_{\mathrm{x}}\left(\mathrm{FA}_{0.83} \mathrm{Cs}_{0.17} \mathrm{PbI}_{3}\right)_{1-\mathrm{x}}(\mathrm{x}=0,0.01$, 0.02, 0.04) based PPDs without encapsulation, in humid air under $68 \mathrm{~mW} \mathrm{~cm}{ }^{-2}$ illumination. 


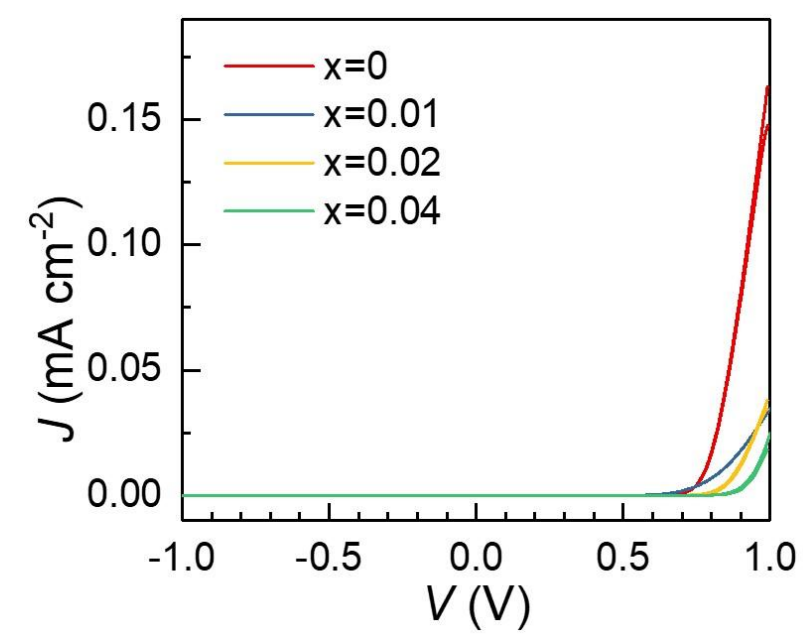

Figure S5. Hysteresis of the $J-V$ curves of PPDs based on $\left(\mathrm{PA}_{2} \mathrm{PbI}_{4}\right)_{\mathrm{x}}\left(\mathrm{FA}_{0.83} \mathrm{Cs}_{0.17} \mathrm{PbI}_{3}\right)_{1-\mathrm{x}}$ $(\mathrm{x}=0,0.01,0.02,0.04)$ with the same scanning ranges (from -1 to $1 \mathrm{~V})$ and the same scanning rate of $50 \mathrm{mV} \mathrm{s}^{-1}$.
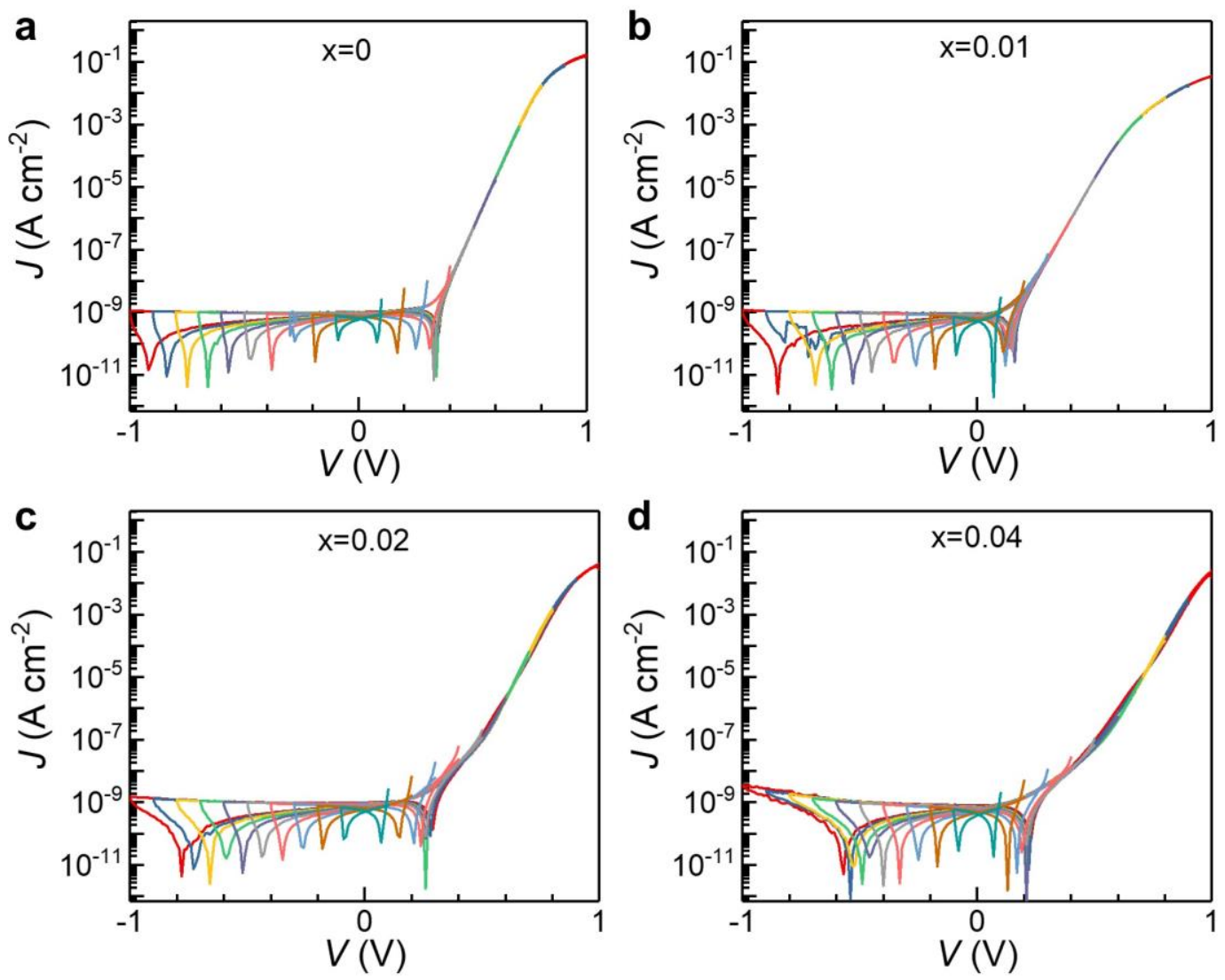

Figure S6. $J-V$ curves of photodiodes based on $\left(\mathrm{PA}_{2} \mathrm{PbI}_{4}\right)_{\mathrm{x}}\left(\mathrm{FA}_{0.83} \mathrm{Cs}_{0.17} \mathrm{PbI}_{3}\right)_{1-\mathrm{x}}$ ((a) $\mathrm{x}=0$, (b) $\mathrm{x}=0.01$, (c) $\mathrm{x}=0.02,(\mathrm{~d}) \mathrm{x}=0.04)$ with various scanning ranges and the same scanning rate of 50 $\mathrm{mV} \mathrm{s}^{-1}$. 


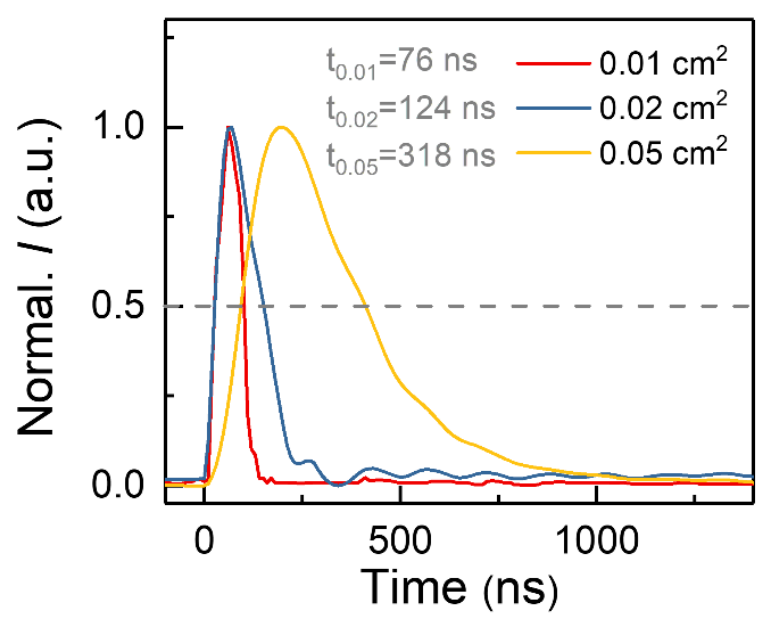

Figure S7. Comparison of the photoresponse of the $\left(\mathrm{PA}_{2} \mathrm{PbI}_{4}\right)_{0.02}\left(\mathrm{FA}_{0.83} \mathrm{Cs}_{0.17} \mathrm{PbI}_{3}\right)_{0.98} \mathrm{PPDs}$ with various device areas.
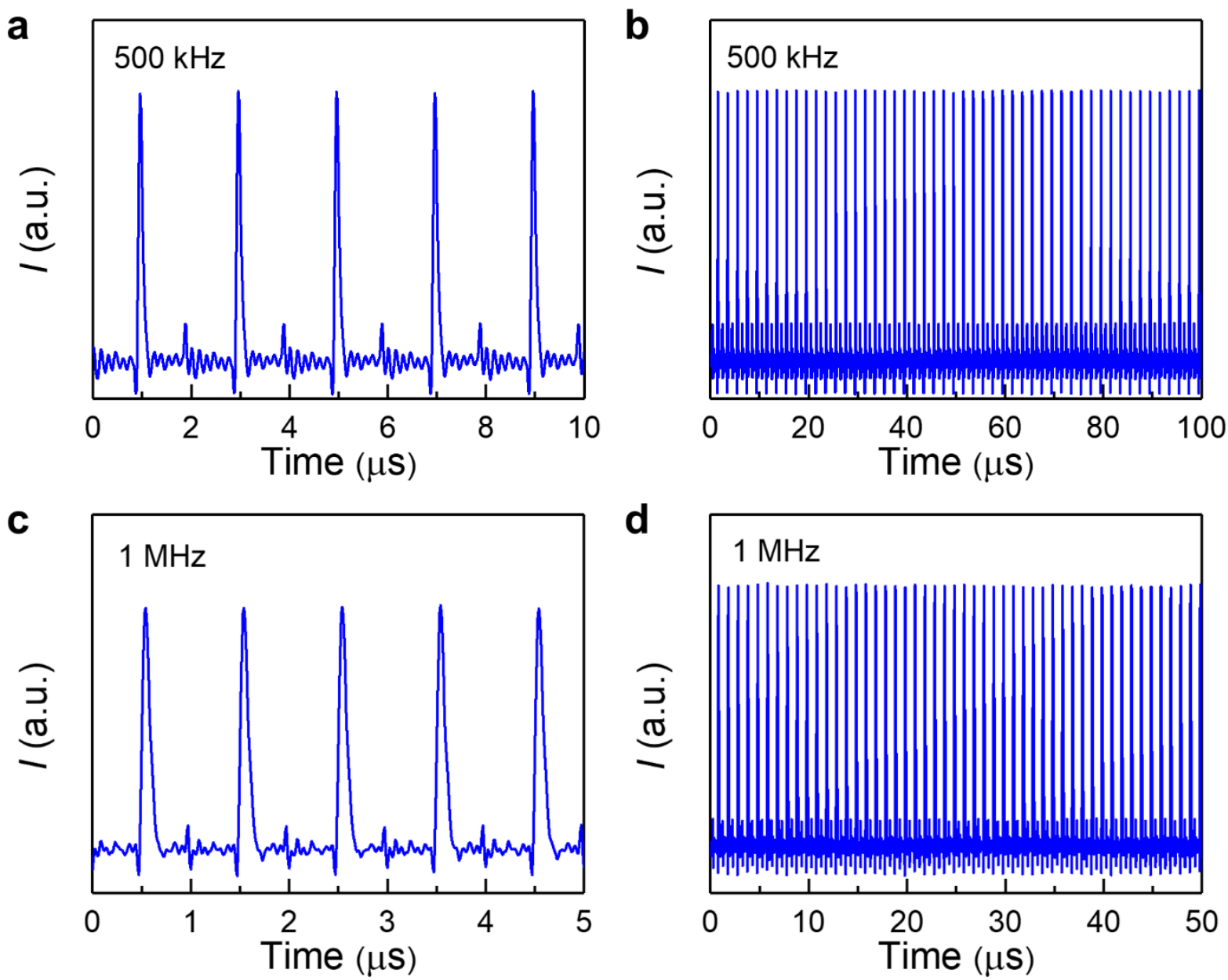

Figure S8. Repeated temporal response for multiple cycles of the $\left(\mathrm{PA}_{2} \mathrm{PbI}_{4}\right)_{0.02}\left(\mathrm{FA}_{0.83} \mathrm{Cs}_{0.17} \mathrm{PbI}_{3}\right)_{0.98} \mathrm{PPDs}$ at $-0.5 \mathrm{~V}$ to a $(\mathbf{a}-\mathbf{b}) 500 \mathrm{kHz}$ and $(\mathbf{c}-\mathbf{d}) 1 \mathrm{MHz}$ modulated picosecond laser. 